\title{
The Effects of Parental Monitoring on Adolescent and Emerging Adult Contribution: A Longitudinal Examination
}

\author{
Goda Kaniušonyte ${ }^{1}$ \\ ${ }^{1}$ Mykolas Romeris University, Vilnius, Lithuania \\ Correspondence: Goda Kaniušonyte, Mykolas Romeris University, Ateities str. 20, Lt-08303, Vilnius, Lithuania. \\ Tel: 370-60-079-759. E-mail: godakan@mruni.eu
}

Received: November 8, 2014

Accepted: December 19, 2014 Online Published: February 17, 2015

doi:10.5539/ijps.v7n1p9

URL: http://dx.doi.org/10.5539/ijps.v7n1p9

\begin{abstract}
The purpose of this study was to explore empirical associations between parental monitoring and for the first time contribution to self, family and community, as outcome of positive youth development, across time among Lithuanian youth. Data for this study are drawn from the first two available waves of an ongoing longitudinal Positive Youth Development research project (POSIDEV), conducted in Lithuania. The sample size for this study was $\mathrm{N}=1098$ (54.5\% girls and 45.5\% boys). Measurements used: parental monitoring scale and three-dimensional contribution scale. Results indicated that parental monitoring at Time 1 predicted all components of contribution: to self $(\beta=.37, p<.001)$, to family $(\beta=.49, p<.001)$ and to community $(\beta=.23$, $\mathrm{p}<.001$ ) at Time 2 . Results also indicated that parental monitoring is more strongly related to contribution in emerging adults group than in adolescents group. To conclude, results of current two-wave study highlighted the importance of the parental monitoring on the outcomes of positive youth development one year later.
\end{abstract}

Keywords: parental monitoring, positive youth development, contribution, adolescence, emerging adulthood

\section{Introduction}

\subsection{Parental Monitoring}

Parental monitoring is one of the central dimensions of parental behavior (Barber, Stolz, Olsen, Collins, \& Burchinal, 2005; Kerr \& Stattin, 2000) that is linked with children's adjustment, development and well-being (e.g. Kerr, Stattin, \& Burk, 2010; Lewin-Bizan, Bowers, \& Lerner, 2010; Napolitanoet et al., 2011). Monitoring is typically operationalized as parental awareness of children's whereabouts and knowledge of their activities and adaptations (Kerr \& Stattin, 2000; Small \& Kerns, 1993). Monitoring does not require a parent to be with a child constantly nor does it imply intrusiveness. Instead it entails an active interest, awareness, and involvement in a child's day-to-day life (Small \& Eastman, 1991). In fact, Stattin and Kerr (2000) pointed out, that "monitoring" is not only a parental activity, but it is also a children's contribution, voluntary descriptions of their free-time activities.

Research has indicated that parental monitoring is a multidimensional construct and that parental knowledge of adolescents' activities is positively associated with a wide range of positive outcomes and negatively associated with a wide range of negative outcomes. For example, parental monitoring is most closely associated with lower levels of problem and delinquent behavior (Kerr \& Stattin, 2000; Pettit, Laird, Dodge, Bates, \& Criss, 2001; Stattin \& Kerr, 2000), substance use (Farmer, Sinha, \& Gill, 2008; Fletcher, Steinberg, \& Williams-Wheeler, 2004; Shillington et al., 2005), vulnerability of adolescents (Small \& Kerns, 1993), risk involvement (Li, Feigelman, \& Stanton, 2000; Li, Stanton, \& Feigelman, 2000), risky sexual behavior (Borawski, Ievers-Landis, Lovegreen, \& Trapl, 2003), and depressive symptoms (Hamza \& Willoughby, 2011). From the positive perspective appropriate monitoring sometimes is seen also as one of the features of authoritative parenting style (Gunnoe, Hetherington, \& Reiss, 1999). An increase in perceived monitoring was associated withgreater academic motivation and, in turn, showed higher grades (Henry, Merten, Plunkett, \& Sands, 2008). In other study perceived parental monitoring predicted future civic engagement (Bebiroglu, Geldhof, Pinderhughes, Phelps, \& Lerner, 2013). In addition, positive parenting, asmeasured by high levels of maternal warmth and parental monitoring, was positively related to individual self-regulatory behaviors, which in turn positively influenced higher levels of positive youth development (PYD) and youth community contributions (Lewin-Bizan et al., 2010; Napolitanoetal, 2011). 
Life period in which parental monitoring takes place is also very important (Tilton-Weaver, 2014). It seems particularly important to study the effects of parental monitoring in emerging adulthood because the very nature of the time period calls for greater amounts, not less, of autonomy granting by parents (Arnett, 2000).

In line with these recent developments of the parental monitoring literature, in this study I sought to further unravel the positive correlates of the parental monitoring by examining associations between contribution as outcome of positive youth development in adolescence and emerging adulthood.

\subsection{Contribution}

Positive youth developmental model particularly emphasizes the importance of family context and parent-child relationships (Chandetal, 2013; Lerner et al., 2005). Positive youth development (PYD) is strengths-based model focused on the main assumption that the youth possess particular strengths and have potential for healthy successful development. PYD model recognizes importance of an individual's and his or her environment's connectivity and how those relationships shape human development (Benson \& Saito, 2000; Benson, 2003; Chandetal, 2013; Fredricks \& Eccles, 2008; Lerner, 2005). The literature has distinguished five positive youth development indicators (called Five C's) stimulating youth's positive developmental results. Those indicators are competence, confidence, connection, character, and caring (Lerner, 2005; Lerneretal, 2005; Roth \& Brooks-Gunn, 2003). In turn, Lerner (2004), Lerner, Dowling and Anderson (2003) have suggested that, when these five $\mathrm{Cs}$ are present in a young person, there emerges a sixth $\mathrm{C}$, contribution. Contribution is conceptualized as behavioral and ideological positive contributions to self, family, community and civil society, arising as an outcome of positive youth development (Geldhof et al., 2014; Lerner et al., 2005). In other words, the young person possesses an identity that specifies that such contributions are predicated on moral and civic duty (Lerner et al., 2003). Recent studies of Positive Youth Development in different countries has found that higher levels of positive youth development components (the Five Cs: Caring, Character, Connection, Confidence, Competence) are positively associated with higher levels of contribution (e.g. Geldhof et al., 2014; Lerner et al., 2005; Mueller et al., 2011).

\subsection{The Current Study}

The purpose of this study was to explore empirical associations between parental monitoring and for the first time contribution to self, family and community across time among Lithuanian youth.

Despite growing body of research on positive parenting practices and positive youth development the findings are contradictory, as in some studies parental monitoring and positive development were strongly related (e.g. Bebiroglu et al., 2013) when in other studies relationships between those two constructs were not found (e.g. Amato \& Fowler, 2002). The question remains what role monitoring plays in positive youth development model. Could monitoring be described as a strengthening factor of family ecological system that predicts positive outcomes? Therefore first aim of this study was to establish longitudinal associations between parental monitoring and contribution.

Previous studies (e.g. Napolitanoetal., 2011; Lewin-Bizan et al., 2010) associated contribution with positive parenting factors, but only measurements concerning contribution to community were used. Considering this, the second aim was to examine these associations including not only contribution to community, but also contribution to self and family.

In addition to these two research questions, I paid close attention to age effects. The two age groups were distinguished. First one consisted of adolescents aged 14-16 years, second -beginning of the emerging adulthood (age 17-19 years). According to Arnett (2000) emerging adulthood extends from the late teens to the mid-to-late 20 s.

In this study, I sought to improve understanding of how parental monitoring affect youths' contribution in adolescence and emerging adulthood. Specifically, effect of monitoring reported by adolescents on contribution to self, family and community was studied for the first time, paying attention to all three aspects of contribution.

\section{Method}

\subsection{Participants}

Data for this study are drawn from the first two available waves of an ongoing longitudinal Positive Youth Development research project, "Mechanisms of promoting positive youth development in the context of socio-economical transformations (POSIDEV)", conducted in Northeastern Lithuania, administrative region of Utena. This study community sample consists of students from five high schools participating in the first two waves (T1 and T2) of the project, collected with a 1-year interval. A total of 1,787 students (9-12 grades) 
participated in the first assessment (participation rate- $98.9 \%$ ). For this current study, only three younger cohorts (10-12 grades at $\mathrm{T} 2, \mathrm{~N}=1308$, participation rate-99.1\%) and only the participants who filled all relevant measures were included in the analyses. Thus, the sample size for this study was $\mathrm{N}=1098(54.5 \%$ girls and $45.5 \%$ boys $)$. The age of participants ranged from 14 to $18(\mathrm{M}=16.61, \mathrm{SD}=1.24)$ at $\mathrm{T} 1$ and from 15 to 19 $(\mathrm{M}=17.1, \mathrm{SD}=0.93)$ at $\mathrm{T} 2$. The sample was diverse in terms of family and socio-economic background sat $\mathrm{T} 1$, $69.6 \%$ of the participants lived with two parents, the rest had a range of other family situations due to parental divorce $(18.2 \%)$, loss $(5.0 \%)$, migration $(3.7 \%)$, or other reasons. With regard to the socio-economic status, $22.5 \%$ received state economic support (free nutrition at school), and in $23 \%$ of cases at least one of the parents was jobless. The sample was homogeneous in terms of ethnic background (i.e., absolute majority of the participants were Lithuanian and $0.6 \%$ were of different ethnic background).

\subsection{Measures}

\subsubsection{Parental Monitoring}

Parental monitoring was assessed by an eight-item scale (Small \& Kerns, 1993). It assesses the extent to which parents know the whereabouts of their youngster after school and at night (e.g. My parent(s) know where I am after school), show an interest in who the teen spends time with, and discuss their child's social plans (e.g. I talk to my parents(s) about the plans I have with my friends), it also covers some youths' tendencies to provide unsolicited information (e.g. I tell my parent(s) whom I'm going to be with before I go out). The PMS scale has been reported to have adequate reliability (Cronbach's alpha $=.87$ ) and predictive validity (Small \& Kerns, 1993). In the present data set, the McDonalds $\omega$ for the PMS is $0.91[0.90,0.91]$ at $\mathrm{T} 1$ and $0.92[0.91,0.93]$ at $\mathrm{T} 2$.

\subsubsection{Contribution}

Contribution was assessed by three-dimensional contribution scale (Truskauskaitè-Kunevičienė, Kaniušonytė, \& Žukauskienè, 2014). The scale consists of three five-item subscales measuring contribution to self (e.g. I like to try different activities), $\omega=0.87[0.85,0.88]$, contribution to family (e.g. I often show interest in how are my family members doing), $\omega=0.89[0.88,0.91]$ and contribution to community (e.g. I'm engaged in volunteering activities), $\omega=0.91[0.90,0.92]$. CFA showed acceptable model fit $\left(\chi^{2}=344.9, \mathrm{df}=88, \chi^{2} / \mathrm{df}=3.92, \mathrm{CFI}=.93\right.$, RMSEA $=.092[.082, .103])$.

\section{Results}

Means, standard deviations, and correlations among study variables are reported in Table 1. An analysis indicated that contribution to self, to family and to community were interrelated and they were all positively associated with parental monitoring at $\mathrm{T} 1$ and $\mathrm{T} 2$.

Table 1. Means (M), standard deviations (SD), and inter correlations among study variables (parental monitoring at both time points and contribution to self, family and community)

\begin{tabular}{llllllll}
\hline \multicolumn{8}{c}{ Age of the participants } \\
\hline & $\begin{array}{l}\text { Total } \\
(\mathrm{N}=1098)\end{array}$ & $\begin{array}{l}14-16 \text { years } \\
(\mathrm{n}=707)\end{array}$ & $\begin{array}{l}17-19 \text { years } \\
(\mathrm{n}=390)\end{array}$ & & & & \\
& $\mathrm{M}(\mathrm{SD})$ & $\mathrm{M}(\mathrm{SD})$ & $\mathrm{M}(\mathrm{SD})$ & 2 & 3 & 4 & 5 \\
\hline 1. Parental monitoring T1 & $4.09(.73)$ & $4.06(.77)$ & $4.15(.66)$ & $.59^{* *}$ & $.34^{* *}$ & $.45^{* *}$ & $.24^{* *}$ \\
2. Parental monitoring T2 & $4.06(.77)$ & $4.07(.77)$ & $4.03(.78)$ & & $.46^{* *}$ & $.58^{* *}$ & $.31^{* *}$ \\
3. Contribution to Self & $3.85(.72)$ & $3.87(.72)$ & $3.81(.72)$ & & & $.73^{* *}$ & $.49^{* *}$ \\
4. Contribution to Family & $3.76(.78)$ & $3.77(.78)$ & $3.76(.77)$ & & & & $.40^{* *}$ \\
5. Contribution to & $3.23(.94)$ & $3.20(.95)$ & $3.27(.90)$ & & & & \\
$\quad$ Community & & & & & & & \\
\hline
\end{tabular}
Note. ${ }^{* *} \mathrm{p}<.01$.

Structural Equation Model (SEM) analyses was conducted using Mplus 6.12 (Muthén \& Muthén, 1998-2012). A model (see Fig.1) consisting of five latent variables: parental monitoring at T1 and T2 (i.e., defined by eight observed indicators), contribution to self (i.e., defined by five observed indicators), contribution to family (i.e., 
defined by five observed indicators) and contribution to community (i.e., defined by five observed indicators) was tested. The model fit was tested by means of the (a) $\chi^{2} / \mathrm{df}$ ratio that should be lower than 5 (Marsh \& Hocevar, 1985), (b) the Comparative Fit Index (CFI), that should be higher than .90, and (c) the Root Mean Square Error of Approximation (RMSEA), that should be lower than .08 (Kline, 2011).

Results indicated that the model fitted the data reasonably $\left(\chi^{2}=1997.45, \mathrm{df}=424, \chi^{2} / \mathrm{df}=4.71, \mathrm{CFI}=.93\right.$, RMSEA $=.058[.056, .061])$ and revealed that monitoring at Time 1 predicted all components of contribution: to self $(\beta=.37, \mathrm{p}<.001)$, to family $(\beta=.49, \mathrm{p}<.001)$ and to community $(\beta=.23, \mathrm{p}<.001)$. In order to test if path coefficients were comparable (in two age groups - adolescence and emerging adulthood) I used a multi-group approach. Findings indicated that the model in which regression coefficients were free $\left(\chi^{2}=2665,62, \mathrm{df}=900\right.$, $\chi^{2} / \mathrm{df}=2.96, \mathrm{CFI}=.93$, RMSEA $=.06[.057, .062]$ ) to vary across the two groups (younger than 17 at T1 vs. older than 17 at T1) was significantly different $\left(\Delta \chi^{2}=10.12, \Delta \mathrm{df}=3, \mathrm{p}=.017 ; \Delta \mathrm{CFI}=.00, \Delta \mathrm{RMSEA}=.00\right)$ from the model in which regression coefficients were fixed equal $\left(\chi^{2}=2675,75, \mathrm{df}=903, \chi^{2} / \mathrm{df}=2.96, \mathrm{CFI}=.92\right.$, RMSEA $=.06[.057, .062]$ ) across groups. Thus, parental monitoring is more strongly related to contribution in emerging adults.

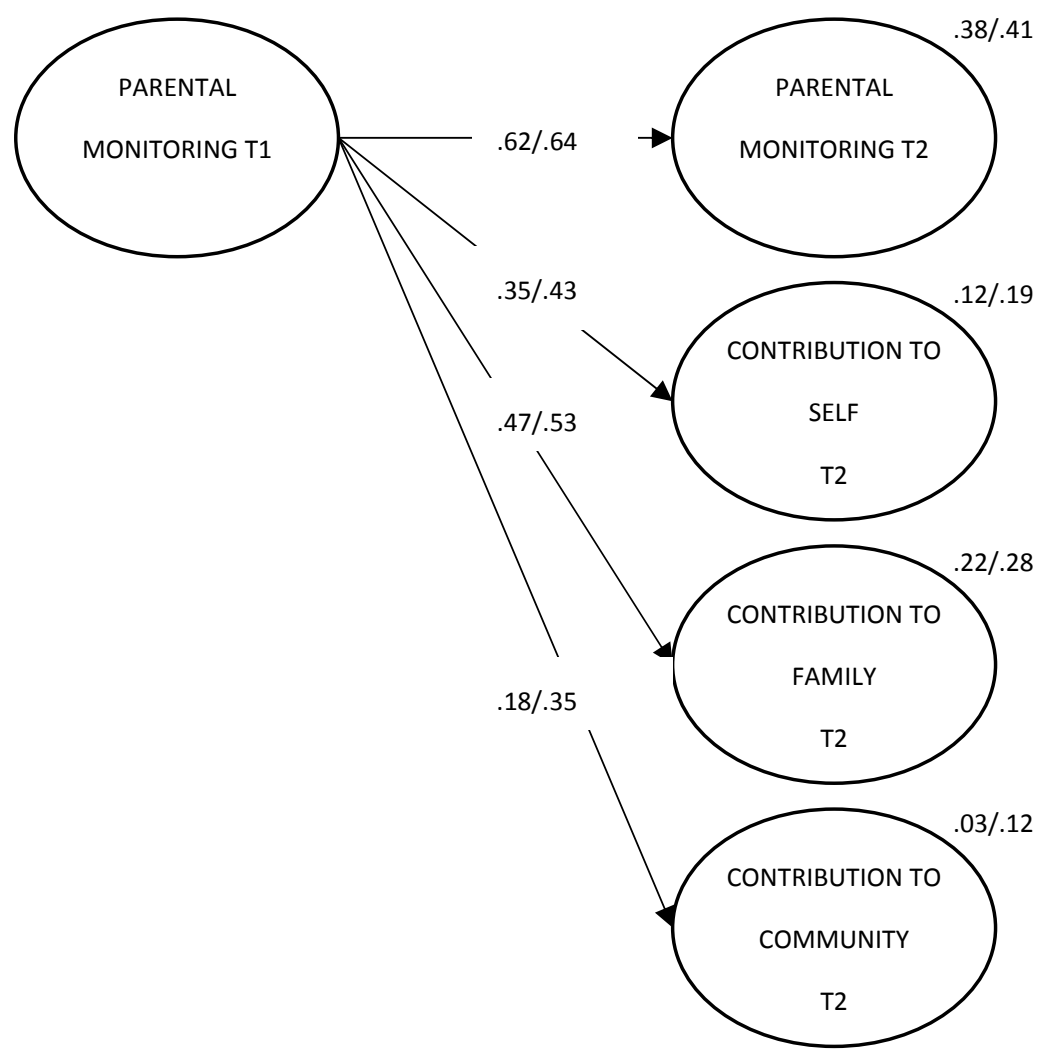

Figure 1. Standardized solution of the model tested for the adolescents (age 14-16 at Time 1) and emerging adults (age 17-18 at Time 1)

Note. Values for adolescents are in front of slash (/), and values for the emerging adults are behind the slash; $\mathrm{p}<$ 0.001 .

\section{Discussion}

The present study sought to examine the relations between parental monitoring as positive parenting factor and contribution to self, family and community. Results of current two-wave study highlighted the importance of the parental monitoring on the outcomes of positive youth development one year later.

\subsection{Parental Monitoring and Contribution}

Evidence presented here suggests that parental monitoring is strongly related to contribution as outcome of PYD. Parental monitoring significantly predicts all three dimensions of contribution: contribution to self, to family and to community. It supports and expands there cent findings (Bebiroglu et al., 2013; Lewin-Bizan et al., 2010; 
Napolitanoetal, 2011) that parental monitoring is important in predicting and forming civic engagement and contribution to community. Moreover in this study for the first time contribution to self and family was added into analysis, parental monitoring predicted contribution to self and family even better than contribution to community and explained more variance in these two dimensions. This result could mean that parental knowledge about their children is related to child's willingness to invest in self and family more than it's related to involvement in the community, but this association could not be interpreted directionally, reciprocal process should be considered.

\subsection{From Adolescence to Emerging Adulthood}

Secondly I found that pattern of perceived parental monitoring differs between age groups, that means that for emerging adults parental monitoring is even more important and better predicts contribution to self, family and community. Furthermore, parental monitoring in emerging adults' group explained more variance in all three contribution dimensions, than in younger group. This lends support to the idea that in middle adolescence monitoring is less effective, than in late adolescence or even in the emerging adulthood (Tilton-Weaver, 2014). In another study on emerging adulthood parental monitoring and parental knowledge was also associated with more positive developmental outcomes (Padilla-Walker, Nelson, Madsen, \& Barry, 2008). The other explanation could be related to conception of monitoring itself. As Kerr and Stattin (2010) stated monitoring is more parents' knowledge of youngster's whereabouts than active surveillance and that knowledge is gained from youngster willing disclosure. If knowledge itself is not completely correct it could impact its predictive power. This idea is supported by Jensen and colleagues (2004) research, which concludes that emerging adults is less accepting of lying and reported less frequent lying to parents, compared to adolescents (Jensen, Arnett, Feldman, \& Cauffman, 2004).

It is important to emphasize that contribution to community show most different pattern of contribution dimensions across age. Results show that in younger group parental monitoring predicts contribution to community relatively weakly, and for older group that prediction notably increases. It suggests the idea that appropriate monitoring in the late adolescence is important in formation of civic values and morality (which reflect contribution to community) in the beginning of emerging adulthood. Comparing adolescents' and emerging adults' means of contribution to self, family and community supports the idea that nowadays emerging adults are less civically engaged than thinking about how to create a good and satisfying life for themselves and those they love (Arnett, 2007). But the finding that outcomes related to community increases with age on the other hand bears further examination.

\subsection{Limitations and Suggestions for Future Research}

The study has several limitations that should be noted. The sample of emerging adults in current study covered only the beginning of this period, it would be important to explore these connections including older participants. Second limitation is that the model postulate directional effect which is quite simplistic. Indeed scholars state that parent-child relationship is reciprocal process (Amato \& Fowler, 2002) and further research is needed, then, to clarify these processes including also more parenting factors to view these connection from holistic perspective.

\section{Conclusion}

Parental monitoring significantly predicts contribution to self, family and community and this effect is stronger in emerging adulthood.

\section{Acknowledgements}

This research was funded by the European Social Fund under the Global Grant measure, VP1-3.1-ŠMM-07-K-02-008.

\section{References}

Amato, P. R., \& Fowler, F. (2002). Parenting practices, child adjustment, and family diversity. Journal of Marriage and Family, 64(3), 703-716. http://dx.doi.org/10.1111/j.1741-3737.2002.00703.x

Arnett, J. J. (2000). Emerging adulthood: A theory of development from the late teens through the twenties. American psychologist, 55(5), 469. http://dx.doi.org/10.1037/0003-066X.55.5.469

Arnett, J. J. (2007). Suffering, selfish, slackers? Myths and reality about emerging adults. Journal of youth and adolescence, 36(1), 23-29. http://dx.doi.org/10.1007/s10964-006-9157-z

Barber, B. K., Stolz, H. E., Olsen, J. A., Collins, W. A., \& Burchinal, M. (2005). Parental support, psychological control, and behavioral control: Assessing relevance across time, culture, and method. Monographs of the society for research in child development (Serial no. 282), 70(4), 1-147. 
Bebiroglu, N., Geldhof, G. J., Pinderhughes, E. E., Phelps, E., \& Lerner, R. M. (2013). From family to society: The role of perceived parenting behaviors in promoting youth civic engagement. Parenting, 13(3), 153-168. http://dx.doi.org/10.1080/15295192.2013.756352

Benson, P. L. (2003). Developmental assets and asset-building community: Conceptual and empirical foundations. In Developmental assets and asset-building communities (pp. 19-43). Springer US. http://dx.doi.org/10.1007/978-1-4615-0091-9_2

Benson, P. L., \& Saito, R. N. (2000). The scientific foundations of youth development. In Trends in Youth Development (pp. 135-154). Springer US.

Borawski, E. A., Ievers-Landis, C. E., Lovegreen, L. D., \& Trapl, E. S. (2003). Parental monitoring, negotiated unsupervised time, and parental trust: The role of perceived parenting practices in adolescent health risk behaviors. Journal of Adolescent Health, 33(2), 60-70. http://dx.doi.org/10.1016/S1054-139X(03)00100-9

Chand, N., Farruggia, S., Dittman, C., Wai, J., Sanders, C., \& Sanders, M., (2013). Promoting positive youth development: Through a brief parenting intervention program. Youth Studies Australia, 32(1), 29-36.

Farmer, A. Y., Sinha, J. W., \& Gill, E. (2008). The effects of family religiosity, parental limit-setting, and monitoring on adolescent substance use. Journal of ethnicity in substance abuse, 7(4), 428-450. http://dx.doi.org/10.1080/15332640802508176

Fletcher, A. C., Steinberg, L., \& Williams-Wheeler, M. (2004). Parental influences on adolescent problem behavior: Revisiting Stattin and Kerr. Child development, 75(3), 781-796. http://dx.doi.org/10.1111/j.1467-8624.2004.00706.x

Fredricks, J. A., \& Eccles, J. S. (2008). Participation in extracurricular activities in the middle school years: Are there developmental benefits for African American and European American youth? Journal of Youth and Adolescence, 37(9), 1029-1043. http://dx.doi.org/10.1007/s10964-008-9309-4

Geldhof, G. J., Bowers, E. P., Boyd, M. J., Mueller, M. K., Napolitano, C. M., Schmid, K. L., ... Lerner, R. M. (2014). Creation of short and very short measures of the five Cs of positive youth development. Journal of Research on Adolescence, 24(1), 163-176. http://dx.doi.org/10.1111/jora.12039

Gunnoe, M. L., Hetherington, E. M., \& Reiss, D. (1999). Parental religiosity, parenting style, and adolescent social responsibility. The Journal of Early Adolescence, 19(2), 199-225. http://dx.doi.org/10.1177/0272431699019002004

Hamza, C. A., \& Willoughby, T. (2011). Perceived Parental Monitoring, Adolescent Disclosure, and Adolescent Depressive Symptoms: A Longitudinal Examination. Journal of Youth and Adolescence, 40(7), 902-915. http://dx.doi.org/10.1007/s10964-010-9604-8

Henry, C. S., Merten, M. J., Plunkett, S. W., \& Sands, T. (2008). Neighborhood, parenting, and adolescent factors and academic achievement in Latino adolescents from immigrant families. Family Relations, 57(5), 579-590. http://dx.doi.org/10.1111/j.1741-3729.2008.00524.x

Jensen, L. A., Arnett, J. J., Feldman, S. S., \& Cauffman, E. (2004). The right to do wrong: Lying to parents among adolescents and emerging adults. Journal of Youth and Adolescence, 33(2), 101-112. http://dx.doi.org/10.1023/B:JOYO.0000013422.48100.5a

Kerr, M., \& Stattin, H. (2000). What parents know, how they know it, and several forms of adolescent adjustment: further support for a reinterpretation of monitoring. Developmental psychology, 36(3), 366. http://dx.doi.org/10.1037/0012-1649.36.3.366

Kerr, M., Stattin, H., \& Burk, W. J. (2010). A reinterpretation of parental monitoring in longitudinal perspective. Journal of Research on Adolescence, 20(1), 39-64. http://dx.doi.org/10.1111/j.1532-7795.2009.00623.x

Kline, R. B. (2011). Principles and practice of structural equation modeling. Guilford press.

Lerner, R. M. (2005). Promoting positive youth development: Theoretical and empirical bases. White paper prepared for the Workshop on the Science of Adolescent Health and Development, National Research Council/Institute of Medicine. Washington, DC: National Academies of Science.

Lerner, R. M., Dowling, E. M., \& Anderson, P. M. (2003). Positive youth development: Thriving as the basis of personhood and civil society. Applied Developmental Science, 7(3), 172-180. http://dx.doi.org/10.1207/S1532480XADS0703_8 
Lerner, R. M., Lerner, J. V., Almerigi, J. B., Theokas, C., Phelps, E., Gestsdottir, S., ... Von, E. A. (2005). Positive Youth Development, Participation in community youth development programs, and community contributions of fifth-grade adolescents findings from the first wave of the 4-H study of Positive Youth Development. The Journal of Early Adolescence, 25(1), 17-71. http://dx.doi.org/10.1207/S1532480XADS0703_8

Lewin-Bizan, S., Bowers, E. P., \& Lerner, R. M. (2010). One good thing leads to another: Cascades of positive youth development among American adolescents. Development and psychopathology, 22(4), 759-770. http://dx.doi.org/10.1017/S0954579410000441

Li, X., Feigelman, S., \& Stanton, B. (2000). Perceived parental monitoring and health risk behaviors among urban low-income African-American children and adolescents. Journal of Adolescent Health, 27(1), 43-48. http://dx.doi.org/10.1016/S1054-139X(99)00077-4

Li, X., Stanton, B., \& Feigelman, S. (2000). Impact of perceived parental monitoring on adolescent risk behavior over 4 years. Journal of adolescent health, 27(1), 49-56. http://dx.doi.org/10.1016/S1054-139X(00)00092-6

Marsh, H. W., \& Hocevar, D. (1985). Application of confirmatory factor analysis to the study of self-concept: First-and higher order factor models and their invariance across groups. Psychological bulletin, 97(3), 562. http://dx.doi.org/10.1037/0033-2909.97.3.562

Mueller, M. K., Phelps, E., Bowers, E. P., Agans, J. P., Urban, J. B., \& Lerner, R. M. (2011). Youth development program participation and intentional self-regulation skills: Contextual and individual bases of pathways to positive youth development. Journal of adolescence, 34(6), 1115-1125. http://dx.doi.org/10.1016/j.adolescence.2011.07.010

Napolitano, C. M., Bowers, E. P., Gestsdottir, S., Depping, M., Von, E. A., Chase, P., \& Lerner, J. V. (2011). The role of parenting and goal selection in positive youth development: A person-centered approach. Journal of adolescence, 34(6), 1137-1149. http://dx.doi.org/10.1016/j.adolescence.2011.07.008

Padilla-Walker, L. M., Nelson, L. J., Madsen, S. D., \& Barry, C. M. (2008). The role of perceived parental knowledge on emerging adults' risk behaviors. Journal of Youth and Adolescence, 37(7), 847-859. http://dx.doi.org/10.1007/s10964-007-9268-1

Pettit, G. S., Laird, R. D., Dodge, K. A., Bates, J. E., \& Criss, M. M. (2001). Antecedents and behavior-problem outcomes of parental monitoring and psychological control in early adolescence. Child development, 72(2), 583-598. http://dx.doi.org/10.1111/1467-8624.00298

Roth, J. L., \& Brooks-Gunn, J. (2003). Youth development programs: Risk, prevention and policy. Journal of adolescent health, 32(3), 170-182. http://dx.doi.org/10.1016/S1054-139X(02)00421-4

Shillington, A. M., Lehman, S., Clapp, J., Hovell, M. F., Sipan, C., \& Blumberg, E. J. (2005). Parental Monitoring: Can It Continue to Be Protective Among High-Risk Adolescents? Journal of Child \& Adolescent Substance Abuse, 15(1), 1-15. http://dx.doi.org/10.1300/J029v15n01_01

Small, S. A., \& Eastman, G. (1991). Rearing adolescents in contemporary society: A conceptual framework for understanding the responsibilities and needs of parents. Family relations, 40(4), 455-462. http://dx.doi.org/10.2307/584904

Small, S. A., \& Kerns, D. (1993). Unwanted sexual activity among peers during early and middle adolescence: Incidence and risk factors. Journal of Marriage and the Family, 55(4), 941-952. http://dx.doi.org/10.2307/352774

Stattin, H., \& Kerr, M. (2000). Parental monitoring: A reinterpretation. Child development, 71(4), 1072-1085. http://dx.doi.org/10.1111/1467-8624.00210

Tilton-Weaver, L. (2014). Adolescents' Information Management: Comparing Ideas About Why Adolescents Disclose to or Keep Secrets from Their Parents. Journal of youth and adolescence, 43(5), 803-813. http://dx.doi.org/10.1007/s10964-013-0008-4

Truskauskaitė-Kunevičienė, I., Kaniušonytė, G., \& Žukauskienė, R. (2014). What does it mean to "Contribute" in an Eastern-European Context? In The Development and Psychometrical Evaluation of the new Scale. Presented at the special topic meeting of SRCD, Prague, Czech Republic. 


\section{Copyrights}

Copyright for this article is retained by the author(s), with first publication rights granted to the journal.

This is an open-access article distributed under the terms and conditions of the Creative Commons Attribution license (http://creativecommons.org/licenses/by/3.0/). 